\title{
DIREITO \& DESENVOLVIMENTO: \\ O PAPEL DO DIREITO NO DESENVOLVIMENTO ECONÔMICO
}

\section{LAW \& DEVELOPMENT: THE ROLE OF LAW IN ECONOMIC DEVELOPMENT}

Recebido: 28.08.2017

Aprovado: 23.10.2017

Ivo Teixeira Gico Júnior*

RESUMO: A pobreza éa regra na história da humanidade. Mesmo hoje, em pleno século XXI a maior parte da população mundial vive em condições de pobreza. Normalmente, a explicação oferecida para tamanho subdesenvolvimento é a carência de investimentos, políticas macroeconômicas deletérias ou falta de capital humano. A abordagem neoinstitucionalista defende que tais explicações são secundárias. O subdesenvolvimento decorre, em última instância, das escolhas que cada sociedade faz e tais escolhas são formatadas e limitadas pelas instituições (regras e normas) que estruturam a interação humana em uma dada comunidade. A principal instituição formal a regular as interações humanas em toda e qualquer economia capitalista desenvolvida é o direito. O presente artigo se propõe a discutir justamente o papel do sistema jurídico e sua contribuição para o desenvolvimento.

Palavras-chave: Desenvolvimento. Instituições. Direito.

JEL: O1, O12, O17, Ko

\begin{abstract}
Poverty is the rule in human history. Even today, in the $21^{\text {st }}$ century, most of the world population lives in poverty. Many academics explain the massive underdevelopment as a result of lack of investment, harmful macroeconomic policies or lack of human capital. The neoinstitutionalist approach suggests that those explanations are secondary. At the end of the day, underdevelopment results directly from each society' choices and those choices are formatted and limited by institutions (rules and norms) that structure human interaction within a given community. The main institution to regulate human interaction in any development capitalist economy is the law. This paper discusses the role of law and its contribution to development.
\end{abstract}

Keywords: Development. Institutions. Law.

JEL: O1, O12, O17, Ko

\footnotetext{
* Professor de Direito Econômico no Programa de Doutorado no UniCeuB, Brasília. Doutor em Economia (UnB), Doutor em Direito (USP), Mestre com Honra Máxima (Columbia Law School). E-mail: < gico@ghdadvogados.com. br $>$.
} 


\section{INTRODUÇÃO}

Do ponto de vista histórico, a pobreza tem sido a condição natural da humanidade, não a exceção (MADDISON, 2006). Tem havido uma redução substancial no nível de pobreza em várias regiões do mundo, todavia, em locais como a África Subsaariana a pobreza tem aumentado e não diminuído (CHEN; RAVALLION, 2004). Alguns países conseguiram romper a barreira da pobreza e tornaram-se desenvolvidos. Em tais regiões, a população goza não apenas de um nível superior de conforto material e de oportunidades, mas também possui mais acesso ao processo político, aos mercados (que são mais amplos e mais competitivos), a ideias diversas, informação e conhecimento. Também há pobres em países desenvolvidos, mas em uma parcela muito inferior ao resto da população e em condições substancialmente distintas dos pobres em países subdesenvolvidos, que via de regra são miseráveis.

Em países desenvolvidos, as pessoas podem abrir e fechar negócios livremente; podem participar do processo político independentemente de sua origem, classe, cor ou religião; podem formar organizações civis e criar movimentos políticos a custos muito inferiores aos de seus pares em países subdesenvolvidos. No mesmo sentido, populações de países desenvolvidos invariavelmente gozam de sistemas jurídicos maduros e bastante estáveis que são integralmente aplicáveis à maioria absoluta da população, não apenas aos integrantes das elites dominantes.

Nesse sentido, como explicar a existência de sociedades tão distintas? Muitos especialistas, ortodoxoseheterodoxos, alegarameaindaalegam queo subdesenvolvimento seria o resultado de falta de investimento, um problema que poderia - em tese - ser resolvido com a atração de poupança estrangeira mediante políticas de juros altos, pela transferência direta de capital mediante ajuda de organismos internacionais ou simplesmente pelo endividamento estatal. Em larga medida, essa visão, em um sabor ou em outro, ainda é dominante na discussão dos macroeconomistas.

Curiosamente, em vários países, apesar de o investimento ter aumentado, o esperado desenvolvimento sustentável não se materializou. Em geral, são países em que há elevados custos de transação, grupos econômicos poderosos e setores informais consideráveis. Quando simplesmente aumentar o investimento não foi suficiente, muitos passaram a criticar as políticas macroeconômicas. Os mercados não estavam funcionando adequadamente por culpa de políticas estatais. Era necessário que os mercados fossem liberalizados para poderem funcionar. Era necessário que os preços fossem "corretos" para transmitir à sociedade os reais custos de oferecer cada bem.

Vários países seguiram essa cartilha e implementaram diversas medidas macroeconômicas ortodoxas, como responsabilidade fiscal, controle inflacionário, câmbio flutuante, mas, novamente, o esperado desenvolvimento não se materializou. A nova explicação foi a falta de capital humano ou, simplesmente, educação. Novamente várias medidas foram tomadas para aumentar o número de anos da população em geral nas escolas. Contudo, a produtividade da força de trabalho não aumentou. A qualidade da educação em geral é baixa e os retornos associados também são baixos, o que desincentiva o investimento em educação. 
De acordo com a abordagem neoinstitucionalista adotada no presente artigo, a falta de investimento, políticas deletérias e falta de capital humano são explicações secundárias. O subdesenvolvimento decorre, em última instância, das escolhas que cada sociedade faz e tais escolhas são formatadas e limitadas pelas instituições (regras e normas) que estruturam a interação humana em uma dada comunidade (NORTH, 2007 [1990]).

A principal instituição formal a regular as interações humanas em toda e qualquer economia capitalista desenvolvida é o direito. Não há um único país desenvolvido cuja população não goze, em larga medida, de um sistema jurídico sólido e extremamente complexo, aplicado por cortes e tribunais independentes. O presente artigo se propõe a discutir justamente o papel do sistema jurídico e, portanto, do direito em países desenvolvidos e sua contribuição para o seu desenvolvimento.

Para tanto, discutiremos na Seção 2 as razões normalmente associadas ao desenvolvimento e as razões pelas quais tais explicações são insatisfatórias quando excluídas as instituições. Na Seção 3, discutiremos as explicações tradicionais oferecidas pela literatura neoinstitucionalista para o fato de vários países não terem conseguido fazer a transição para o desenvolvimento e, em especial, a necessidade de um arcabouço institucional que permita a criação e proteção de um mercado de trocas impessoais. Na última seção discutiremos as instituições normalmente associadas com o desenvolvimento (propriedade, contratos e finanças) com suas respectivas áreas jurídicas. Demonstraremos que as instituições pró-mercado efetivamente essenciais ao desenvolvimento são normalmente associadas ao direito privado, enquanto as instituições estruturantes do Estado e do jogo político, que protegem o próprio mercado são associadas ao direito público, muitas vezes ignoradas ou pouco enfatizadas.

\section{EXPLICAÇÕES TRADICIONAIS PARA O SUBDESENVOLVIMENTO}

Mais de $80 \%$ da humanidade vive hoje em países que o Banco Mundial considera subdesenvolvidos (SHIRLEY, 2008) e mesmo com os enormes avanços identificados em países como China e Índia, quase metade da população mundial vive na pobreza (CHEN \& RAVALLION, 2004). A verdade é que poucos países que eram pobres ao final da $2^{\underline{a}}$ Guerra Mundial possuem hoje renda per capita próxima da dos países desenvolvidos, com a notável exceção dos países exportadores de petróleo. Um dos exemplos de transição mais marcante é a Coréia do Sul, por não envolver a entrada em blocos econômicos, como é o caso da República Tcheca, da Hungria, da República Eslovaca e da Eslovênia.

Em 1960, o PIB per capita da Coréia do Sul era aproximadamente igual ao de Gana, todavia, em 2005, o PIB per capita da Coréia do Sul ajustado pela paridade do poder de compra era oito vezes maior que o de Gana (MADDISON, 2006). Até hoje há debates acerca de como a Coréia do Sul conseguiu tamanho avanço (CHANG, 2008 [2007]) e porque outros países não conseguiram. Já o Brasil é um exemplo de meio termo entre sucesso e fracasso e que ninguém consegue explicar satisfatoriamente por que está onde está e como fazer para ir adiante.

A busca pelo cálice sagrado da receita para o desenvolvimento tem sido 
empreendida com baixo grau de sucesso por economistas de todos os matizes (LAL, 2002 [1983]). Desde a década de 6o, pesquisadores e especialistas têm abraçado e abandonado várias explicações possíveis para o subdesenvolvimento e tentado alcançar o desenvolvimento de várias formas. Os principais "motores" testados foram: investimento e inovação tecnológica; políticas macroeconômicas pró-mercado; e formação de capital humano. Um resumo mais detalhado dessas aventuras e desventuras não cabe neste trabalho, mas é oferecido por William Easterly (2002 [2001]).

Deinício, cabedizer que nenhuma dessas estratégias foi suficientepara transformar países subdesenvolvidos em desenvolvidos, nem para explicar a situação de cada um. Uma das razões para essa incapacidade é que tais explicações ignoram sumariamente a importância das instituições.

Por exemplo, podemos dizer que investimento não está correlacionado com crescimento em vários aspectos (SHIRLEY, 2008). Essa afirmação pode parecer um pouco estranha para defensores de teorias neoclássicas do crescimento ou mesmo para Keynesianos e Novos Keynesianos, mas se considerarmos que o investimento apenas estimula o crescimento quando há oportunidades econômicas e incentivos para empreender produtivamente, a relação entre investimento e crescimento parece ser menos direta. Ela é mediada por instituições.

Invariavelmente países pobres são penalizados por barreiras não econômicas à entrada, ameaças a negócios que não a competição, exceto para alguns poucos integrantes das elites dominantes. Para todos os demais, os custos de transação associados à criação, administração e liquidação de um empreendimento são inflados por burocracias corruptas e ineficientes, pela insuficiente ou inexistente aplicação das leis contra crimes, fraudes e expropriações, pela dificuldade de fazer valer contratos, por regulações parciais e excludentes, pela fragilidade da defesa do direito de propriedade, bem como por carência de mecanismos eficazes para pressionar políticos para que respondam a essas ineficiências.

A consequência desse ambiente institucional é que o determinante predominante para o sucesso ou o fracasso de um empreendimento está mais ligado a quem o empresário conhece (economia personalista) do que a capacidade empreendedora e de inovação do empresário, o que, obviamente, reduz substancialmente a pressão competitiva e incrementa os incentivos para comportamentos oportunistas.

Países subdesenvolvidos são governados por uma coalização de poderosas elites que, para se manterem ou por puro receio, limitam o acesso de grupos excluídos à política, educação, organizações e à própria economia. Esse estado de exclusão é tão prevalecente na história da humanidade que Douglas North e outros denominaram esse arranjo institucional de "Estado Natural" (NORTH; WALLIS; WEINGAST, 2009). Mesmo sociedades que nominalmente possuem regras constitucionais, eleitorais e outras instituições associadas a uma democracia podem ser consideras Estados Naturais se tais regras, na prática, limitam o acesso às elites dominantes.

Em um ambiente competitivo, em que as conexões políticas são relevantes para o resultado do jogo econômico, é natural que empresas excluídas ou pertencentes a grupos 
excluídos sejam penalizadas com altos custos de transação impostos pelo governo na forma de burocracia, incerteza e insegurança. Já empresas politicamente influentes conseguem burlar ou ao menos mitigar substancialmente tais custos, o que desequilibra a concorrência.

Um dos resultados naturais da imposição estatal de custos de transação desproporcionais a empresas não pertencentes à elite é o crescimento considerável do setor informal. A informalidade é um traço característico dos países subdesenvolvidos. Diante de custos consideráveis, muitos empreendedores optam por não entrar no mercado e outros optam por entrar à margem da lei, na informalidade. A informalidade gera custos privados e sociais. Empresas informais vivem em constante insegurança; não podem participar de licitações ou negociar com grandes empresas; não podem exportar ou importar por canais oficiais; não têm acesso ao sistema financeiro; são mais vulneráveis à brutalidade policial e à corrupção da burocracia e fiscais; e têm menos acesso ao Judiciário. Além disso, para evitar chamar atenção, negócios informais devem manter-se pequenos, o que impede que empresas eficientes cresçam. Não é à toa que a informalidade é inversamente correlacionada com desenvolvimento (AYYAGARI; BECK; DEMIRGÜÇ-KUNT, 2005).

A este ponto deve ser relativamente óbvio que a estrutura jurídica de um país, não apenas aquela constante dos livros e das leis, mas a efetivamente praticada, possui uma enorme importância para a forma como investimentos gerarão ou não riqueza para um povo. A existência de instituições (regras) ruins pode não apenas impedir o investimento, como pode distorcê-lo de forma a canalizá-lo para empresas menos eficientes ou para finalidades socialmente indesejáveis, distorcendo o mercado. Tais distorções são capazes de limitar a inovação e o crescimento.

Como a simples transferência de capital ea realização de investimentos para países subdesenvolvidos não se mostrou suficiente para gerar crescimento, muito pensadores passaram a defender que os mercados precisavam ser corrigidos por meio de políticas macroeconômicas para que funcionassem adequadamente. A existência de grandes déficits fiscais, políticas monetárias inflacionárias, taxas de câmbio supervalorizadas e barreiras ao comércio internacional estaria impedindo que os mercados funcionassem adequadamente e, portanto, limitando a possibilidade e a utilidade dos investimentos a serem realizados (SHIRLEY, 2008).

Durante os anos 80 e na década de 9o, muitos países se esforçaram para implementar pelo menos algumas dessas mudanças, como o Brasil, o Chile, a Argentina e o México. No entanto, a profundidade, a extensão e o sucesso de tais políticas variaram substancialmente entre os países, pois a verdade é que as escolhas políticas dependem da estrutura institucional e organizacional de cada país. Em outras palavras, que medidas foram implementadas, quando e como depende fundamentalmente do arcabouço institucional que comanda o jogo político, isto é, as regras políticas determinam quais são os tópicos e os grupos aos quais os políticos devem atender. Tais interesses, por sua vez, determinam que medidas políticas serão implementadas e se o foco será no curto ou no longo prazo. 
Enfim, políticas macroeconômicas são o resultado conjunto do sistema econômico, político e de crenças de uma dada sociedade, razão pela qual sem a compreensão de todas as variáveis, qualquer alteração de uma única medida pode não alcançar os resultados desejados. Sociedades são sistemas complexos de natureza não ergódica.

A mesma lógica se aplica ao problema da educação em países subdesenvolvidos. Mesmo naqueles em que recursos adequados foram destinados ao sistema educacional, muitas vezes, as organizações e as instituições são tais que os agentes não possuem incentivos para aumentar a qualidade do ensino.

No Brasil, por exemplo, existe uma forte resistência a se tentar vincular a remuneração dos professores da rede pública ao desempenho de seus alunos em testes padronizados. A burocracia que controla a educação superior impede a concorrência e controla a qualidade dos cursos que existem (incumbentes) com base apenas em critérios quantitativos e não qualitativos. Muitas vezes, o incentivo dos políticos é com a construção de novas escolas, o que permite a realização de lucrativos contratos, bem como a criação de uma comunidade clientelista que recebe posições na burocracia (algo comum na história do Distrito Federal). Essa estrutura de incentivos pune aqueles que tentam excluir clientes da estrutura e desincentiva a qualidade.

Em resumo, oargumento não é que investimento, boas políticas macroeconômicas e educação não geram desenvolvimento, mas sim que assumir que tais variáveis se comportariam da mesma forma em países desenvolvidos e subdesenvolvidos é errado. É necessário que o arcabouço institucional adequado esteja presente. Em outras palavras, sem os incentivos certos para os agentes, o sistema social pode gerar resultados indesejáveis ainda que outras variáveis estejam presentes.

\section{EXPLICAÇÕES NEOINSTITUCIONALISTAS PARA O SUBDESENVOLVIMENTO}

Instituições são "restrições desenvolvidas pelos seres humanos que estruturam a interação humana" (NORTH, 2007 [1990], p. 3), o que inclui restrições escritas e formais como leis e constituições, bem como restrições informais e tácitas como normas sociais, convenções e códigos de conduta autoimpostos. As instituições ou regras do jogo são desenvolvidas pela humanidade para prover um mínimo de estrutura para a interação humana em um mundo marcado pela incerteza. Instituições reduzem a incerteza e o risco ao tornar as ações dos demais agentes mais previsíveis.

Avner Greif (2006) define instituições de forma mais ampla como um sistema compartilhado de crenças, normas internalizadas, regras e organizações que motivam, permitem e guiam indivíduos a seguirem uma determinada regra de conduta, gerando, dessa forma, padrões de comportamento. Ao contrário de North, para Grief, a eficácia é um elemento essencial da definição de instituição. Nesse sentido, uma regra imposta pelo Estado que não gere alteração de comportamento não constitui uma instituição.

A essa altura é obvio que uma das instituições mais importante nas sociedades modernas, se a mais importante, é o direito, isto é, o conjunto de obrigações impostas pelo Estado apoiadas em sanções estatais em caso de descumprimento. 
Por outro lado, todos os aspectos da interação humana, por mais simples que possam parecer, contêm alguma forma de instituição informal que regulamenta essa interação. Por exemplo, a forma de se pegar bagagens nas esteiras dos aeroportos. Em Genebra, Suíça, ao se aproximar das esteiras, os passageiros se mantêm a uma distância de 2 a 3 metros da esteira. Não há faixas no chão ou guardas que imponham essa distância, mas todos parecem segui-la rigorosamente. Mesmo estrangeiros, como este Autor, que não sabem de início da regra informal, rapidamente a percebem e se ajustam ao comportamento social. Já no aeroporto de Guarulhos, em São Paulo, a conduta é completamente diversa. A maioria dos passageiros se espreme e se aperta para sair rapidamente do avião e se posicionam da forma mais próxima possível da esteira. Aqueles que assim não procedem, rapidamente são bloqueados por outros passageiros que se esgueiram por qualquer brecha para ficar colados na esteira. Um suíço que chegasse em Guarulhos seria rapidamente empurrado para trás da multidão de passageiros e teria de esperar quase todos pegarem suas bagagens para ter acesso à sua. Um brasileiro que estivesse em Genebra provavelmente se encontraria sozinho ao lado da esteira e provavelmente perceberia que há algo de estranho no seu comportamento. A maioria se retrai assim que percebe este fato e a regra da distância permanece em funcionamento. Exemplos semelhantes são a forma como se guiam carros em Bangladesh, Beijing, Washington, Brasília ou como se posicionar em uma escada rolante.

Estes simples exemplos demonstram como não são apenas as regras formais que constituem instituições, mas também regras de comportamento que as pessoas internalizam ao decorrer do tempo. O resultado é a combinação de tais regras com as regras estatais que são efetivamente feitas valer (enforced), isto é, possuem eficácia.

Toda sociedade possui um conjunto de instituições fundamentais que proveem o arcabouço básico para a interação entre seus membros, tais como constituições, códigos e normas de conduta amplamente aceitas. Apesar de muitas regras e hábitos mudarem com alguma frequência, essas instituições fundamentais são mais persistentes e enraizadas. Tais instituições são o que chamamos de 'arcabouço ou ambiente institucional'. O arcabouço institucional de uma sociedade é o resultado de sua história. As elites estruturam as instituições fundamentais para perpetuar o seu poder e algumas dessas estruturas persistem, mesmo quando tais elites não estão mais no poder (viscosidade institucional). Essa persistência pode decorrer não apenas do fato de algum grupo poderoso ainda a fazer valer, mas também de sua incorporação ao sistema de crenças da sociedade, que passa a crer que o mundo se comporta ou deveria se comportar dessa forma, que os demais agentes se comportam ou deveriam se comportar dessa forma. Tais instituições se tornam impregnadas no tecido social. São muito difíceis de mudar e impossíveis de se ignorar (NORTH, 2005).

Normas internalizadas podem persistir mesmo quando conflitam com o que observadores externos classificariam como interesse próprio. Um exemplo disso é o caso da água encanada de Conacri, Guiné (SHIRLEY, 2008). No final dos anos 8o, o sistema de água de Conacri estava em colapso. Mais de $40 \%$ da população não era atendida, a qualidade da água era ruim, havia interrupções frequentes, não havia fundos para 
reparos e expansão, além de que 60\% da água era perdida em vazamentos, desvios ou simplesmente não cobrados. Para resolver o problema, o Governo da Guiné arrendou o sistema de fornecimento de água a um consórcio de empresas privadas para operá-lo na capital e em algumas cidades grandes. O preço do fornecimento foi ajustado para recuperar a rede, um sistema de cobrança mais eficiente foi instalado e as conexões irregulares foram eliminadas. Como resultado, a maioria dos consumidores agora tinha custos maiores para ter acesso à água. Tais custos tornaram-se ainda maiores quando o próprio Governo parou de pagar suas contas.

No novo sistema de Conacri, as taxas para quem usava pouca água eram módicas, por outro lado, eram substanciais para os usuários de grandes volumes. Todavia, a maioria das casas era de usuários intensivos, pois a conexão era na realidade compartilhada com várias famílias. Além disso, as famílias que mantinham a conexão não cobravam dos vizinhos pelo uso da água, razão pela qual apenas as famílias mais ricas tinham condições de manter tais conexões, de custos elevados, e o acesso à água era restrito.

Uma pesquisa realizada no local (SHIRLEY; MÉNARD, 2002) indicou que em Conacri havia fortes 'regras morais' contra a cobrança de água pelos vizinhos, provavelmente porque no passado uma conexão de água sinalizava à sociedade que o seu detentor tinha influência com as elites dominantes, além de os preços serem menores e raramente ser cobrado pelo gasto. Não obstante, quando as circunstâncias mudaram, essa norma social de compartilhamento sem cobrança tornou-se inadequada e, como era difícil mudar, acabou resultando em poucas pessoas tendo condições de manter uma conexão e, portanto, em um menor acesso.

Em Abidjan, Costa do Marfim, foi implementado um arranjo similar de privatização do sistema de água encanada, que também resultou em preços maiores, contudo, não houve problema de acesso. Primeiro, porque Abidjan era mais rica, mas mais relevante, porque em Abidjan os vizinhos que compartilhavam uma conexão dividiam a conta (MÉNARD; CLARKE, 2002). A moral da história é que ao contrário do que prega a teoria ortodoxa, o mecanismo mercado não funciona da mesma forma em todas as sociedades. A depender do arcabouço institucional vigente, uma solução que foi bem-sucedida em uma dada comunidade pode fracassar miseravelmente em outra. Em suma, 'as instituições importam para o desenvolvimento'.

As economias de mercado modernas que foram bem-sucedidas são caracterizadas por instituiçõesqueapoiam trocas mercadológicasimpessoais, algumas vezes envolvendo longas distâncias e longos períodos de tempo. Os mecanismos primitivos de trocas, como a troca imediata, a reputação e o conhecimento pessoal ainda são importantes e existem, mas essas formas tradicionais de troca existem em paralelo com trocas complexas e anônimas realizadas entre vários níveis de estranhos governados por reguladores, tribunais e a polícia. Mercados desenvolvidos são sempre caracterizados por mecanismos institucionais que permitem a realização de trocas complexas, temporalmente distantes e, mais importante, entre desconhecidos. A impessoalidade das trocas amplia os mercados, a especialização e, assim, o crescimento econômico. 
Para que estes mercados impessoais possam funcionar, são necessários dois tipos de instituições - as redutoras de custos de transação e as protetoras de comportamento oportunista (expropriação). Toda transação tem custos: encontrar o parceiro, receber e oferecer informações, negociar preço, conferir o produto, monitorar os termos acordados, fazer valer os termos acordados e punir aqueles que desviam (COASE, 1993 [1937]). A compreensão dos custos de transação é fundamental para a compreensão do desenvolvimento, pois onde há custos de transação, há oportunidades de trocas perdidas.

Normalmente, as instituições relacionadas com a redução dos custos de transação estão relacionadas com o direito privado, isto é, o direito que regulamenta as relações jurídicas entre os agentes privados. No entanto, também são relevantes as intervenções estatais estruturais que constroem mercados, como a criação e uniformização da moeda, a estruturação do sistema financeiro, a proteção do sistema de direito de propriedade e contratual (Judiciário e Polícia), o que no Brasil ficou constitucionalmente conhecido como a ordem econômica.

Além disso, reduzir os custos de transação não é suficiente. A criação, manutenção e expansão dos mercados pressupõe a existência de instituições que protejam os particulares de expropriação por parte do Estado e demais grupos de poder. Deve ser no interesse das elites proteger a propriedade privada dos agentes envolvidos na troca, de outra forma, os agentes terão incentivos a desperdiçar recursos protegendo-se do Estado, ocultando a troca de seu conhecimento ou, simplesmente, não realizando a troca. Estados efetivos monopolizam o uso legítimo da força para manter a estabilidade e a paz, para proteger os indivíduos e sua propriedade, para fazer valer os contratos e as leis. Todavia, um Estado forte o suficiente para fazer isso também é forte o suficiente para expropriar seus cidadãos e subjugar as pessoas (WEINGAST, 1993).

A realização de trocas pressupõe restrições críveis ao poder estatal de apropriar-se dos ganhos. Assim como instituições que protegem contratos determinam o escopo das transações que ocorrerão em um dado mercado, pela determinação de quais barganhas são protegíveis (logo, críveis), instituições que limitam a coerção estatal e privada influenciam a própria decisão dos indivíduos em trazer seus bens para o mercado, isto é, a existência do mercado em si (GRIEF, 2005).

Economias de mercado avançadas desenvolveram instituições que limitam oabuso de poder por parte do Estado, instituições que são críveis para os potenciais investidores, por exemplo, instituições que incentivam as trocas podem ser (i) reputação pessoal; (ii) reputação dentro de redes de negócios baseadas em família, religião ou outras redes sociais; (iii) reféns; (iv) normas de condutas comerciais e (v) códigos comerciais (lex mercatoria) e civis (GREIF, 2006). Já instituições que limitam o poder estatal podem ser (i) horizonte de tempo do ditador; (ii) normas militares de não-intervenção; (iii) ameaça de revolta; (iv) financiamento, ajuda, alianças e ameaças internacionais; (v) eleições e normas democráticas; (vi) separação de poderes de assembleias e tribunais; e (vii) federalismo.

Note que, grosso modo, tais grupos de instituições correspondem justamente aos corpos jurídicos a que pertencem o direito privado e o direito público. Explicar como tais 
instituições surgiram nos países desenvolvidos é uma tarefa muito complexa para um artigo, mas algumas explicações caras aos neoinstitucionalistas podem ser obtidas em North (2007 [1990]), Grief (2006) e um resumo interessante em Shirley (2008). Da mesma forma, não há consenso na literatura acerca do porquê tais instituições não surgiram em países subdesenvolvidos. As explicações mais comuns são herança colonial (e.g. NORTH, 2007 [1990]; SHIRLEY, 2008; PORTA, 1997); dotações (i.e. recursos naturais) mais heranças coloniais (ACEMOGLU; JOHNSON; ROBINSON, 2001); conflitos (TILLY, 1992) e crenças e normas (GREIF, 2006).

Apesar de ter havido avanços consideráveis no entendimento das instituições que levamaodesenvolvimento, nossoentendimentoacercadoquelevaaosubdesenvolvimento ainda é muito limitado. Além disso, nossa compreensão sobre como as instituições mudam ainda é muito parcial. Instituições são persistentes, mas também são endógenas (SHIRLEY, 2008), o desafio é avançar além dessas abstrações e encontrar evidências que sejam mais úteis para os elaboradores de políticas públicas.

\section{A RELAÇÃO ENTRE O DIREITO E O DESENVOLVIMENTO}

É dentro desse contexto teórico que se inclui a relevância do direito para o desenvolvimento econômico. A história tem demonstrado que nenhuma sociedade capitalista moderna conseguiu emergir sem uma infraestrutura jurídica ampla e complexa que simultaneamente conseguisse garantir a existência de um mercado impessoal e sem proteger parcela substancial dos cidadãos da espoliação por elites dominantes. Parece haver, portanto, alguma correlação entre desenvolvimento e um sistema jurídico sólido.

Quanto maior for um dado mercado, mais seus integrantes poderão dividir trabalho e se especializar. A especialização gera eficiência e, com isso, aumenta a riqueza social. Não é à toa que em cidades pequenas médicos e advogados são normalmente generalistas. A demanda restrita por trabalhos específicos, isto é, o tamanho do mercado, não permite que seus integrantes se especializem e, com isso, essas comunidades tornamse menos prósperas. A uniformidade do direito aplicável ao mercado permite que este se alargue. Nessa linha, a criação dos Estados Nacionais contribuiu significativamente para o desenvolvimento dos povos europeus. A imposição de uma única ordem jurídica a grandes extensões territoriais e comunidades reduziu substancialmente os custos de transação entre elas e expandiu os mercados.

Deuma forma mais geral, 'a fonte da prosperidade é a cooperação humana'. Quanto mais os membros de uma dada comunidade cooperam, menos recursos a sociedade desperdiçará com a proteção de ativos (e.g. contratação de seguranças, milícias armadas, sistemas de alarme) e com atividades meramente distributivas (e.g. roubo, saque, fraudes). Tais atividades não são produtivas e, portanto, são desperdícios de riqueza. Os recursos poupados nestas sociedades podem ser vertidos para outras atividades mais produtivas, como a produção de bens e serviços e sua troca. Esse é o famoso dilema entre fazer ou tomar.

Obviamente, a troca em qualquer mercado pressupõe que os agentes barganhando sejam capazes de identificar e mutuamente reconhecer a titularidade dos respectivos 
produtos a serem trocados. Sem a noção clara do que pertence a cada um, a insegurança pode gerar conflitos sobre a propriedade e caímos novamente no mundo não-cooperativo. Torna-se melhor tomar a fazer. A regulamentação acerca do que pertence a cada um e o que se pode realizar com cada bem é regulado pelo direito civil, em especial pelo 'direito de propriedade'.

O direito de propriedade pode ser inclusivo ou exclusivo. Na Roma Antiga, por exemplo, sob certas circunstâncias, escravos poderiam ter propriedade privada e, com isso, alguns conseguiam comprar sua liberdade. Já no período escravocrata brasileiro, havia dois sistemas. Nas plantações de cana-de-açúcar e café, onde o desempenho de cada escravo dependia apenas de seu próprio esforço e era barato monitorá-lo, os escravos não podiam possuir propriedade. Os incentivos a trabalhar vinham da ameaça e dos castigos físicos. Já na mineração, onde o desempenho dependia também de elementos aleatórios, cuja monitoração era custosa, aos escravos era permitido ficar com parte do que conseguissem extrair, gerando incentivos para que produzissem sem o necessário custo de monitoramento.

Outro exemplo claro de como o direito de propriedade pode limitar quem tem acesso aos mercados é a antiga proibição de mulheres possuírem propriedade. Tal regra excluía as mulheres do mercado, da possibilidade de acumular riquezas e, assim, as marginalizavam. Mais importante que isso, sem poder participar do mercado, as mulheres eram mais vulneráveis à elite masculina dominante.

No exemplo anterior na cidade de Conacri, Guiné, as conexões de água encanada eram, na prática, propriedades coletivas e, por isso, estavam expostas ao problema de recursos comuns (common pool) conhecido como tragédia dos baldios. Cada conexão era sobre-explorada e os usuários não enfrentavam os custos sociais do que estavam usufruindo, o que acabou por gerar uma escassez. O direito de propriedade lida justamente com estas questões e como cada sociedade resolve seus problemas de alocação de recursos e esforços, logo, tem um impacto significativo sobre seu desempenho econômico de uma dada sociedade.

Note que o direito de propriedade não se resume aos direitos de uso (ius utendi), gozo (ius fruendi) e disposição (ius abutendi, que inclui o direito de alterar e de transferir) de bens materiais. À medida que a tecnologia evolui e os custos de produção caem, a propriedade intelectual se torna cada vez mais relevante para a riqueza das nações. Quando produzir é barato, a ideia inovadora é que agrega valor. Apenas a título de exemplo, tomemos o caso do licenciamento compulsório de alguns medicamentos de combate à AIDS. O Estado brasileiro decretou que poderia fabricar tais medicamentos ou comprar de terceiros, independentemente do consentimento das empresas que detinham a patente de tais medicamentos. Na prática, mitigou substancialmente o direito de propriedade dos inventores de tais medicamentos. Qual a relevância desse tipo de postura para o desenvolvimento econômico brasileiro?

É fato que os contribuintes brasileiros pagarão menos pelo bem-sucedido programa de combate à AIDS em território nacional. Todavia, tendo em vista que a propriedade dos inventores foi mitigada, também é provável que as empresas brasileiras 
não invistam em inovações na área de medicamentos que sejam de interesse do Governo brasileiro, pois correm o sério risco de terem suas patentes licenciadas compulsoriamente. É mais provável que a energia inovadora seja canalizada para outras áreas onde a propriedade não foi relativizada e, portanto, a lucratividade tende a ser maior, como o desenvolvimento de softwares ou mesmo remédio para cachorros.

Independentemente da clareza e da robustez dos direitos de propriedade de um dado país, não basta as pessoas serem titulares dos resultados de seus esforços, é preciso que elas sejam capazes de trocar os frutos de seus trabalhos com outras pessoas e, assim, possam usufruir integralmente dos ganhos da especialização. Se uma pessoa fosse senhora de tudo o que produz, mas não pudesse trocar com outros, teria que produzir quase tudo para sua sobrevivência, como era feito na Idade Média, e não haveria qualquer ganho com a especialização. Na prática, não haveria mercado.

A possibilidade de troca (ius abutendi) permite a existência de um mercado, mas não resolve o problema da confiança recíproca. Como fazer com que o outro lado do negócio cumpra com sua parte na barganha quando o adimplemento é diferido no tempo?

Na Antiguidade e na Idade Média, o problema da desconfiança recíproca era resolvido por mecanismos primitivos, basicamente a reputação. Em uma pequena comunidade, caso um membro não honrasse seu compromisso, todos saberiam de seu inadimplemento rapidamente e ele dificilmente conseguiria fazer negócio novamente. Sua própria sobrevivência o impelia a cooperar e não trapacear.

O problema é que esse mecanismo restringe o tamanho do mercado, pois só funciona em pequenas comunidades onde todos se conhecem e, portanto, restringe os potenciais ganhos com a especialização. Para resolver esse problema, foram criados mecanismos reputacionais dentro de redes sociais, como a família, a religião ou profissionais, como as guildas. Assim, ainda que um agente não conhecesse pessoalmente uma determinada pessoa, se ele era parte daquela rede social, então, era confiável. Pelo menos em um primeiro momento. Novamente, tais redes são de custosa implementação e não funcionam muito bem com grandes comunidades. Outros mecanismos foram inventados pela humanidade.

Uma história mais detalhada desse desenvolvimento pode ser obtida em outros locais (e.g. GREIF, 2006), mas o que importa para o presente trabalho é que as sociedades modernas superaram o problema da confiança recíproca com o chamado direito contratual. Essa é a área do direito que determina quem pode contratar, como e em que termos. Assim como a propriedade, o direito de contratar pode ser inclusivo ou exclusivo. De qualquer forma, o 'direito contratual' é a instituição formal que - combinado com a propriedade - dá suporte à existência de um mercado amplo e impessoal nas sociedades capitalistas modernas.

Outra questão bastante cara à economia do desenvolvimento é a necessidade do acúmulo de capital. Quanto mais sofisticado for o empreendimento ou quanto maior a escala mínima viável, maior a quantidade de capital necessária para sua realização e mais improvável que um único indivíduo tenha o capital exigido ou que esteja disposto a 
arriscar tanto. Para resolver esse problema é que existe o chamado 'direito societário', que permite que indivíduos agreguem capitais individuais e formem um ente maior e distinto de seus integrantes, a empresa. As empresas ou corporações têm um papel fundamental no desenvolvimento do mundo moderno. Parcela substancial dos produtos e inovações se origina de grandes empresas e grupos econômicos, tudo, regulado e viabilizado pelo direito societário.

A possibilidade de coordenar esforços em empresas gerou naturalmente a possibilidade de agregar pequenas contribuições de um grande número de pessoas, democratizando o acesso a investimentos que antes eram de exclusividade de poucos ricos. Essa coordenação foi possibilitada pelo direito societário e potencializada pelo 'direito bancário' e de 'mercado de capitais'. O objetivo desses corpos jurídicos é regular e viabilizar que o público em geral participe, a baixíssimos custos de transação, de grandes empreendimentos. Nas sociedades desenvolvidas, é um instrumento de dispersão de risco e democratização do capital. É o ápice da impessoalidade do mercado e de sua extensão quase que global.

O direito societário e o bancário resolvem o problema de acúmulo de capital necessário para manter e replicar o funcionamento do capitalismo atual. Lamentavelmente, sua implementação e funcionamento não ocorreram de forma igual em todos os países e, por exemplo, no Brasil, serviu apenas para concentrar ainda mais poder nas mãos de famílias e pequenos grupos que já dominavam a economia nacional. A pobre regulação e a permissividade da legislação permitiram que, historicamente, acionistas controladores abusassem de acionistas minoritários, o que enfraqueceu o mercado de capitais brasileiro.

E aqui devemos abandonar um pouco o direito privado e passarmos ao direito público, pois em todas as análises estava implícito que tanto o direito de propriedade quanto o direito contratual, societário e bancário seriam protegidos pela sociedade por meio de terceiros desinteressados. Normalmente estes terceiros são tribunais de justiça. Um Judiciário forte e independente é outra característica das sociedades capitalistas desenvolvidas. É ele que permite que os agentes negociem livremente e, caso alguém não cumpra a sua parte, seja obrigado a fazê-lo ou compensar devidamente os prejuízos decorrentes. Agora, para que o Judiciário seja capaz de fazer valer suas ordens é necessário que outra organização esteja a seu serviço, a Polícia. Desobedecer a uma ordem judicial é um crime e cabe à Polícia investigar e prender criminosos. Uma organização completa a outra.

Além do Judiciário, é necessário que haja regras que instruam e limitem a atuação dos entes públicos em geral, para que o Estado não seja um mero mecanismo de expropriação do cidadão. O corpo de direito que regulamenta tais comportamentos é o 'direito administrativo', responsável por dizer o que pode e o que não pode o administrador no exercício de suas funções. A estruturação e a imposição de limites à Administração Pública (principal) requer regras para os servidores públicos (agentes), inclusive para os momentos em que o Estado está agindo como comprador de bens e tomador de serviços (licitações). A esse conjunto de regras se convencionou chamar de direito administrativo. 
Esse direito público está voltado à estruturação e controle do próprio Estado. É, portanto, estadocêntrico, endógeno. Sua função é organizar e limitar.

Por outro lado, existe um direito administrativo cujo foco não é o próprio Estado e a relação entre seus entes, mas sim o mercado, ou seja, os agentes privados. Nesse sentido, trata-se de um direito administrativo estruturante, exógeno. Para fins didáticos, podemos chamar genericamente esse ramo do direito de 'direito econômico', cujo foco seria justamente viabilizar a criação de uma ordem econômica, no linguajar jurídico, ou, simplesmente, o adequado funcionamento dos mercados, no linguajar econômico.

Se o direito civil e o direito societário permitem a estruturação e funcionamento dos mercados, fato é que em algumas hipóteses a liberdade irrestrita dos agentes pode levar à própria destruição dos mercados. Para combater eventuais práticas que destruam o livre mercado ou resultem em abuso do poder econômico surgiu a faceta antitruste do direito econômico, o 'direito concorrencial' (GICO JR., 2007). O direito concorrencial é uma área do direito administrativo inteiramente voltada ao setor privado e cujo objetivo é proteger a existência e o livre funcionamento dos mercados, elemento essencial para o desenvolvimento. Apenas mercados livres e competitivos levam ao desenvolvimento.

No entanto, em alguns casos, por características estruturais ou tecnológicas dos próprios mercados, a simples liberdade não é suficiente para que esses mecanismos de coordenação funcionem adequadamente. Em outras palavras, os mercados falham. Para tentar suprir essas falhas e fazer com que os mercados voltem a funcionar regularmente (o mais possível), existe um conjunto de ferramentas jurídicas que se convencionou chamar de 'direito regulatório'. O termo direito regulatório é bastante amplo e pode ser usado para significar várias coisas, mas a ideia central é que sua finalidade é corrigir alguma falha de mercado. Todas as agências reguladoras como Anvisa, Anatel, Anp ou Aneel lidam com falhas em seus respectivos mercados regulados.

Nesse sentido, mesmo algumas áreas do direito privado poderiam ser reinterpretadas como formas dedireito regulatório. Por exemplo, o 'direito doconsumidor' é uma espécie de direito regulatório específico para resolver problemas de assimetria de informação e impedir o abuso de poder econômico por parte de fornecedores em contratos de consumo. Já o 'direito do trabalho' regula uma outra forma de contrato, o contrato de trabalho, claramente com finalidades redistributivas e de limitação de abuso de poder econômico.

Obviamente todas essas regras, em todas as áreas, são escolhidas pelo Poder Legislativo. Quanto mais ampla for a representação do povo e mais competitivas forem as eleições de tais representantes, mais democráticas serão as regras e maior a probabilidade de elas serem benéficas para uma parcela significativa da população. Excluindo os países exportadores de petróleo, os países desenvolvidos tendem a ter democracias sólidas e competitivas. O 'direito eleitoral' pode ser entendido como o direito antitruste político, cuja função é proteger a competitividade do mercado político de ideias, no qual todos os cidadãos e grupos políticos devem poder se organizar e livremente competir. Nesse sentido, quanto mais competitivo for o processo político, maiores as chances de os representantes eleitos representarem ideias médias da maioria da população, ergo, 
mais democrática será essa sociedade. Se pudermos pressupor que é possível se falar em racionalidade coletiva, então, quanto melhor o processo eleitoral, mais as leis produzidas por essa legislatura devem aumentar o bem-estar social.

Agora a relação entre todas essas organizações e instituições, bem como das regras fundamentais do jogo político estão consolidadas no 'direito constitucional' e cristalizadas na Constituição Federal. É este documento que, via de regra, estabelece os acordos políticos fundamentais de nossa sociedade e estabelece o arcabouço institucional dentro do qual todo o direito se estrutura e opera. Uma compreensão da ordem econômica de um país depende necessariamente da compreensão do conteúdo dessa Carta Fundamental, que em alguns países como a Inglaterra nem escrita é.

No entanto, em países da América Latina, como o Brasil, o grau de desconfiança (literalmente, ausência de confiança) é tamanho, que os vários grupos políticos inseriram em suas cartas constitucionais todo o tipo de previsão que sequer é constitucional em natureza. A Constituição brasileira, por exemplo, discorre sobre garimpeiros (art. 174, § $3^{\text {o) }}$ e sobre o Colégio Pedro II, no Rio de Janeiro (art. 242, \$2º). Claramente essas matérias não tem qualquer relevância para a estruturação do Estado brasileiro, mas os grupos de interesse, à época da constituinte, foram bem-sucedidos em proteger seus interesses, dado que é mais difícil mudar uma norma constitucional do que uma lei. Ao invés de constituir um prestígio ao direito constitucional, esse tipo de fenômeno, que não é exclusividade brasileira, constitui uma degeneração de toda a estrutura jurídica e pode ser identificado em todas as áreas do direito.

Por fim, a existência e a manutenção do Estado, bem como a existência e a garantia de todo e qualquer direito impõe um custo à sociedade, pelo menos para financiar o aparato estatal que o garanta. Para o bem ou para o mal, esse financiamento não é normalmente espontâneo; o Estado emprega o seu monopólio do uso da força para expropriar seus súditos (JOHNS, 1904) e, por isso, essa atividade muito perigosa. Justamente por que o financiamento do Estado é fundamental para a manutenção do direito enquanto mecanismo de cooperação em larga escala, mas constitui uma violência contra o indivíduo, que as regras dentro das quais pode um Estado moderno realizar tal atividade são extremamente restritivas. Trata-se do 'direito tributário’. Já as regras segundo as quais tais recursos serão gastos estão no 'direito financeiro', que estruturará o orçamento público. Espera-se que em sociedades desenvolvidas hajam mecanismos adequados para limitar efetivamente o poder estatal de expropriação, enquanto a alocação das verbas públicas reflita a decisão democrática dos representantes eleitos em processos competitivos. Apenas assim os indivíduos podem gozar de seus direitos e continuar a confiar no sistema.

De qualquer forma, o que importa aqui é perceber como o direito constitui um conjunto de instituições formais que podem ser estruturadas (ou não) para resolver problemas básicos de cooperação humana. Alguns países foram mais bem-sucedidos nessa estruturação, outros menos. Em alguns ramos do direito, essa ideia de direito como tecnologia para resolver problemas de cooperação está mais clara, em outros apenas o interesse de alguns grupos bem coordenados parece dominar (OLSON, 1999 [1962]). De 
um jeito ou de outro, resta claro que o direito enquanto conjunto de regras formais de uma dada sociedade é fundamental para o seu desempenho e o seu progresso enquanto civilização.

\section{CONCLUSÕES}

Como demonstrado acima, se para a compreensão do desenvolvimento econômico dos países a compreensão das instituições importa, então, o Direito importa e muito. Seu estudo pode revelar como as estruturas de poder de uma dada sociedade se organizam, seus sistemas de crenças e normas internalizadas, bem como os espaços de possível atuação para melhoria. Em um contexto onde é necessário estudar e compreender os custos de transação associados com a produção e distribuição de bens, bem como as formas de organização econômica, o estudo do direito passa a ser fundamental.

É uma pena que muitos economistas que trabalham na elaboração e na implementação de políticas públicas não tenham uma percepção plena da importância do estudo e da compreensão do direito e seu papel de tecnologia de coordenação. Por outro lado, também é lamentável que grande parte dos juristas gaste boa parte de seu tempo apenas discutindo o direito como um sistema teórico, sem conexão com a realidade. Mais preocupados com jogos de palavras e sistematização de conceitos do que com a compreensão e a alteração do mundo real, perdem a oportunidade de perceber que o direito cria incentivos, logo, altera a conduta dos agentes. Os primeiros elaboram soluções parciais para o complexo sistema social cujo resultado, via de regra, não é o esperado ou fica aquém do desejável. Os segundos, na melhor das hipóteses, são desnecessários e, na pior das hipóteses, são verdadeiros obstáculos ao desenvolvimento.

\section{REFERÊNCIAS}

ACEMOGLU, D.; JOHNSON, S.; ROBINSON, J. A. The Colonial Origins of Comparative Development: an empirical investigation. American economic review, 91, n. 5, 2001. 1369-13401.

AYYAGARI, M.; BECK, T.; DEMIRGÜÇ-KUNT, A. Small and medium enterprises across the globe. Washington, DC: World Bank Policy Research Working Paper, 2005.

CHANG, H.-J. Bad Samaritans: the myths of free trade and the secret history of capitalism. New York: Bloombury Press, 2008 [2007].

CHEN, S.; RAVALLION, M. How Have the World's Poorest Fared since the Early 1980s? World Bank Policy Research Working Paper 3341, Washington, DC, 2004.

COASE, R. H. The nature of the firm. In: WILLIAMSON, O. E.; WINTER, S. G. The Nature of The Firm: origins, evolution and development. Oxford: Oxford University Press, 1993 [1937]. p. 18-34. 
EASTERLY, W. The elusive quest for growth: Economists' Adventures and Misadventures in the Tropics. Cambridge: MIT Press, 2002 [2001].

GICO JR., I. T. Cartel - teoria unificada da colusão. São Paulo: Lex, 2007.

GREIF, A. Institutions and the path to the modern economy: lessons from medieval trade. Cambridge: Cambridge University Press, 2006.

GRIEF, A. Commitment, coercion and markets: the nature and dynamics of institutions supporting exchange. In: MÉNARD, C.; SHIRLEY, M. M. Handbook of New Institutional Economics. Dordrecht, The Netherlands: Springer, 2005. p. 727-786.

LAL, D. The poverty of "development economics". London: Institute of Economic Affairs - IEA, 2002 [1983].

MADDISON, A. The World Economy. 1‥ ed. Paris: OECD Publishing, v. 1, 2006.

MÉNARD, C.; CLARKE, G. R. G. Reforming Water Supply in Abidjan, Côte d'Ivoire: A mild reform in a turbulent enviroment. In: SHIRLEY, M. M. Thirsting for Effiency: The Economics and Politics of Urban Water Sector Reform. Oxford: Elsevier Science, 2002. p. $233-272$.

NORTH, D. C. Understanding the process of economic change. Princeton: Princeton University Press, 2005.

Institutions, institutinal change and economic performance. New York: Cambrisge University Press, 2007 [1990].

; WALLIS, J. J.; WEINGAST, B. R. Violence and social orders: A conceptual framwork for interpreting recorded human history. New York: Cambridge University Press, 2009.

OLSON, M. A lógica da ação coletiva. São Paulo: Edusp, 1999 [1962].

PORTA, R. L. et al. Legal determinants of external finance. Journal of finance, 52, 1997. 1131-1150.

SHIRLEY, M. M. Institutions and development. Cheltenham: Edward Elgar, 2008. ; MÉNARD, C. Cities Awash: a synthesis of the country cases. In:

SHIRLEY, M. M. Thirsting for efficiency: The Economics and Politics of Urban Water System Reform. Oxford: Elsevier Science, 2002. p. 1-41. 
TILLY, C. Coercion, capital and european states. Oxford: Blackwell Publishing, 1992.

WEINGAST, B. R. Constitutions as Governance Structures: the political foundations of secure markets. Journal of institutional and theoretical economics, 149, n. 1, Jan 1993. 286-311. 